\title{
Idiopathic thrombocytopenic purpura with normal platelet survival time
}

\author{
G. W. K. DONALDSON, A. C. PARKER, M. McARTHUR, AND J. RICHMOND \\ From the Department of Medicine, The Royal Infirmary, Edinburgh
}

SYNOPSIS Platelet survival has been measured in 16 patients with idiopathic thrombocytopenic purpura. Of this group, three patients had a normal result and surface counting did not show high splenic uptake. The clinical features of these patients are described. These patients have remained well for several years without treatment.

The diagnosis of idiopathic thrombocytopenic purpura is made when a low platelet count is associated with normal or increased numbers of megakaryocytes in an otherwise normal bone marrow and the patient gives no history of exposure to drugs or chemicals, shows no evidence of systemic disease, and little or no splenic enlargement.

The cause is uncertain, but present evidence suggests that many cases may have an autoimmune basis. Platelet antibodies or platelet sensitization (Moulinier, 1955; van de Wiel, Dorfmeyer, and van Loghem, 1961) or megakaryocyte antibodies (McKenna and Pisciotta, 1962) can be demonstrated in a high proportion of patients and the majority respond to corticosteroid therapy, at least for a time. There have also been reports of remission on treatment with other immunosuppressive agents (Richmond, Woodruff, Cumming, and Donald, 1963; Martin, Nowicki, Schubert, and Schubert, 1967). In addition an analogous condition may be associated with other disorders believed to be autoimmune in nature such as disseminated lupus erythematosus and autoimmune haemolytic anaemia. Harrington, Minnich, Hollingsworth, and Moore (1951) showed that transfusion of blood or plasma from patients : with idiopathic thrombocytopenic purpura into normal recipients resulted in thrombocytopenia in $60 \%$ of cases studied. Harrington, Sprague, Minnich, Moore, Aulvin, and Dubach (1953) showed further that the thrombocytopenic effect of patient's plasma was diminished in the absence of the spleen. It has recently been demonstrated that this plasma factor is present in the IgC globulin fraction and is species specific (Shulman, Marder, and Weinrach, 1964).

Received for publication 19 November 1970.
The precise mechanism of production of the thrombocytopenia is uncertain but measurements with radioisotope-labelled platelets favour reduction of the platelet survival time in the peripheral circulation in the majority of patients, with uptake of the labelled platelets predominantly in the spleen or the liver. In the studies of Najean, Ardaillou, Dresch, and Bernard (1967) and Aster and Keene (1969) those patients showing high hepatic sequestration of the platelets were the ones who responded poorly to splenectomy.

In some studies of platelet survival in idiopathic thrombocytopenic purpura there have been occasional patients in whom the platelet life span has been normal. While Najean and his colleagues encountered none in a series of 85 patients, Cohen, Gardner, and Barnett (1961) observed this in four of their patients and Aster and Jandl (1964) in one of their patients.

In studies of various platelet disorders using radioactive chromium $\left({ }^{51} \mathrm{Cr}\right)$ as a platelet label, three individuals in a series of 16 patients with an initial diagnosis of idiopathic thrombocytopenic purpura have been encountered who showed normal platelet survival and it is the purpose of the present paper to draw attention to this atypical group.

\section{Methods}

The 16 patients considered to have the disorder ranged in age from 7 to 70 years. Seven were males and nine females. In four patients splenectomy has been undertaken without effect.

Routine haematological measurements were made using the techniques described by Dacie and Lewis (1968). Detection of platelet antibodies was by the technique of Dausset, Colombani, and Colombani 
(1961) and of megakaryocyte antibodies by the method of Coons (1958).

PLATELET SURVIVAL MEASUREMENTS

A modification of the method of Aas and Gardner (1956) was used. Blood was collected into a Fenwal plastic bag containing EDTA in saline; this was centrifuged $\left(2^{\circ} \mathrm{C}, 20 \mathrm{~min}, 1,000 \mathrm{rpm}\right)$ in an MSE centrifuge. The platelet-rich plasma was transferred into a MRC glass bottle and spun at 2,000 rpm for 15 minutes. The platelet 'button' left after withdrawal of the plasma was resuspended in normal saline. ${ }^{51} \mathrm{Cr}(250-400 \mu \mathrm{c})$ was added and the whole incubated at $25^{\circ} \mathrm{C}$ for an hour. The suspension was made up to approximately $80 \mathrm{ml}$ of normal saline and centrifuged $\left(4^{\circ} \mathrm{C}, 10 \mathrm{~min}, 2,000 \mathrm{rpm}\right)$. The supernatant was kept and the remainder given by intravenous injection. Radioactivity received by the patient was $20-100 \mu \mathrm{c}$.

Blood samples were taken using EDTA as anticoagulant. The platelets were separated by a modification of the silicone flotation technique of Morgan and Szafir (1961). Approximately $5 \mathrm{ml}$ of silicone mixture was added to $15 \mathrm{ml}$ of anticoagulated blood and the whole centrifuged $(10 \mathrm{~min}$, $1,200 \mathrm{rpm}$ ) in an MSE centrifuge. The specific gravity of the silicone mixture lies between that of red cells and platelets and this allows separation of the ${ }^{51} \mathrm{Cr}$-labelled red cells. The major contaminant left is lymphocytes which are not significantly labelled.

The platelet-rich plasma was further purified by centrifugation in $1 \%$ ammonium oxalate and finally resuspended in $3 \mathrm{ml}$ of ammonium oxalate.
This method of separation gave $95-100 \%$ yield of platelets, and radioactive counting was carried out in? a standard well-type scintillation counter.

UPTAKE OF LABELLED PLATELETS BY LIVER AND SPLEEN

These observations on the 12 patients who had not had splenectomy were carried out daily over the precordium, liver, and spleen using a directionats scintillation counter with fairly wide collimation. Counting was continued for three to 10 minutes according to the rate of the count. The sites fot surface counting were as follows: precordiumfourth left intercostal space at the sternal edge? liver-ninth right intercostal space halfway betweeriv the anterior and mid-axillary lines; spleen-over the 10th-11th left intercostal space in the posteriog axillary line.

In an attempt to standardize the results for alf patients and to assess the amount of radioactivity inthe spleen, the surface counts over the spleen at daye 1 or at $50 \%$ of the extinction time, whichever was? the longer, were corrected for decay and divided byo the total amount of injected platelet-bound radioactivity in microcuries (Aster and Jandl, 1964). This is an arbitrary value, the results of which depend ${ }^{-}$ amongst other factors on the counting systeng employed. The equipment used in this study gave 18 counts/second/microcurie at a distance of $10 \mathrm{~cm}$ from the crystal, with a background of 11 counts second.

In order to determine platelet-bound radio activity, two $1 \mathrm{ml}$ aliquots of the platelet infusiong were taken. One was diluted in $200 \mathrm{ml}$ of water. The



Table Results of blood counts

${ }^{1}$ No figures

'By extrapolation 
other was washed in $1 \%$ ammonium oxalate which lysed contaminating red cells, thus releasing the haemoglobin-bound ${ }^{51} \mathrm{Cr}$ into the supernatant. The total radioactivity injected and the proportion of that radioactivity which was bound to platelets could then be calculated (Table).

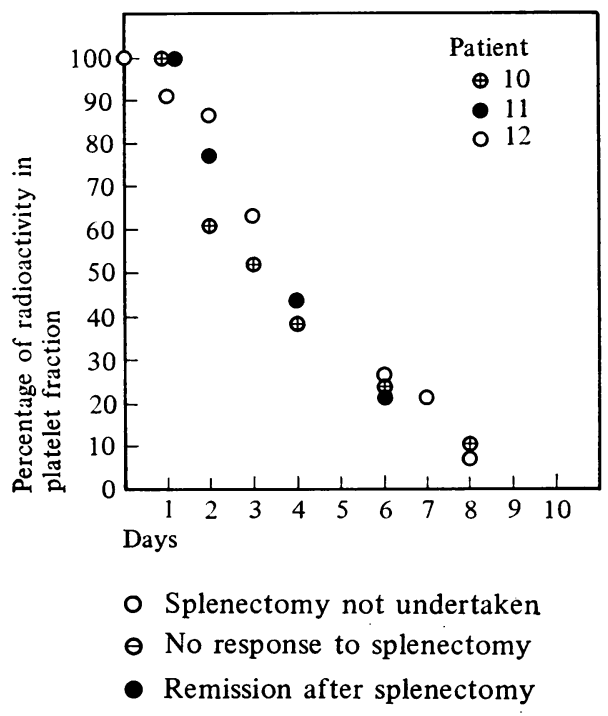

Fig. 1 Platelet survival curves of the three patients described.

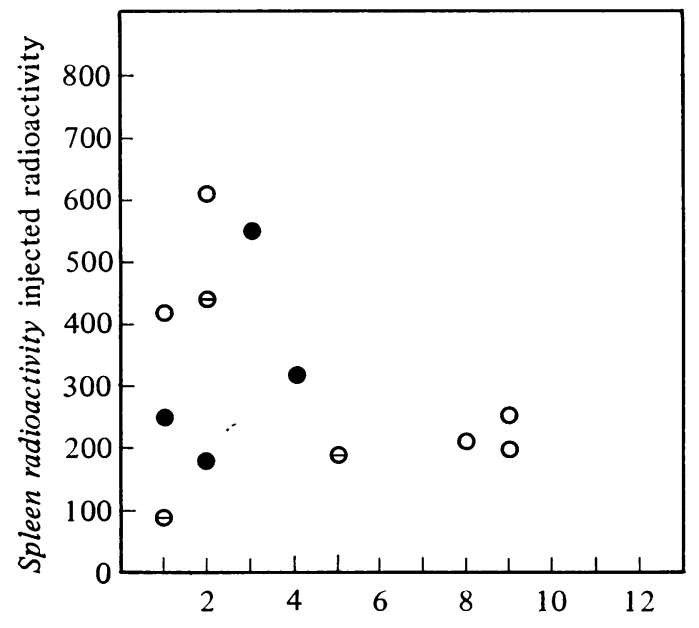

Platelet lifespan (days)

Fig. 2 The platelet life span in 12 patients with idiopathic thrombocytopenic purpura early after diagnosis is plotted against the surface count over the spleen at day 1 or $50 \%$ extinction time, corrected for decay and divided by the total amount of injected platelet-bound radioactivity in microcuries.
Results

Platelet survival time has been expressed as life span or 'extinction time' and is the time in days when the platelet-bound radioactivity falls to less than $5 \%$ of maximum.

The results of platelet survival measurements are given in the Table. It will be seen that 13 patients showed a shortened platelet survival time but three patients (nos. 10,11, and 12) were found to have a result within the normal range (8-11 days).

Platelet survival curves for the patients described in this paper are shown in Figure 1. The radioactivity falls in a curvilinear fashion and becomes negligible in eight to 11 days.

The data used to assess the spleen and liver uptake of radioactivity are given in Figures 2 and 3. Patients 10,11 , and 12 do not have the very high spleen uptake seen in some of the patients with a very short platelet survival time, but they overlap with the remainder which includes patients who have subsequently responded to splenectomy.

The clinical aspects of the three patients with atypical platelet survival time are briefly as follows:

PATIENT NO. 10

This patient, a 38-year-old housewife, presented with bruising of two years' duration in August 1965. Apart from leg pains there were no other symptoms and the menses were normal. On examination mild purpura was evident, particularly on the legs. The spleen could not be palpated. The initial peripheral blood counts were: $\mathrm{Hb} 13.2 \mathrm{~g}, \mathrm{PCV} 41$, MCHC 31 , WCC 12.600 (neutrophils $82 \%$, lymphocytes $11 \%$,

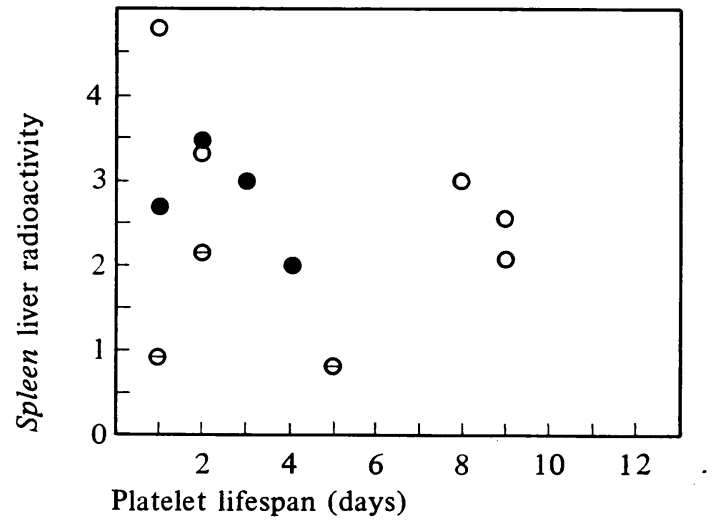

Fig. 3 The platelet life span in the 12 patients with idiopathic thrombocytopenic purpura early after diagnosis is plotted against the ratio of the surface counts over the spleen and liver. 
monocytes $5 \%$, platelets $42 \cdot 000$ ). Marrow examination showed normal haemopoiesis with active budding megakaryocytes. The Coombs test and tests for antinuclear factor and LE cells were negative. The platelet survival time was 10 days.

Prednisone in an initial dose of $60 \mathrm{mg}$ per day was given. Purpura regressed but the platelet count did not rise above 50,000 per $\mathrm{cmm}$. In reducing amounts corticosteroid therapy was continued for one year.

At the last review (in June, 1970) the clinical picture was unchanged; there had been occasional purpura but no other signs or symptoms. The peripheral blood picture was: Hb $13 \cdot 1 \mathrm{~g}$, PCV 44, MCHC 33.5, WCC 16,500 (neutrophils $80 \%$, lymphocytes $14 \%$, monocytes $6 \%$ ), platelets $<10,000$. The marrow appearances were similar to those of four years earlier. Tests for platelet and megakaryocyte antibodies were negative.

PATIENT NO. 11

This girl, aged 7 years, was first seen in May 1963 on account of recurrent epistaxes for the previous three years. Physical examination was entirely negative. The peripheral blood picture showed iron-deficiency anaemia and thrombocytopenia: $\mathrm{Hb}$ was $9.5 \mathrm{~g}$, PCV 27, MCHC 28.5 reticulocytes $4.5 \%$, WCC 7,300 , platelets 40,000 . Marrow examination revealed an increased number of megakaryocytes, but was otherwise normal. The Coombs test was negative and platelet antibodies could not be detected. The platelet survival measurement was normal to six days when it had to be interrupted on account of epistaxis; however, extrapolation of the disappearance curve gave an extinction time of eight days.

The child received corticosteroid therapy in the form of prednisone starting in a dose of $30 \mathrm{mg}$ per day. This was continued in reducing amounts for five months. There was no significant effect on the platelet count, the maximum level reached being 65,000 per $\mathrm{cmm}$.

In the intervening period, the patient has remained relatively well apart from occasional epistaxis. At a recent review (in May, 1970) there were no new clinical findings. The peripheral blood counts were: Hb $10.6 \mathrm{~g}$, MCHC 32.5 , reticulocytes $4 \%$, WCC 5,400 (neutrophils $70 \%$, lymphocytes $24 \%$, monocytes $5 \%$, eosinophils $1 \%$,), platelets 76,000 . The marrow appearances were as at the first examination and megakaryocyte antibodies and serum antinuclear factor could not be detected.

PATIENT NO. 12

This patient, a woman aged 67 , was treated with radioactive iodine for thyrotoxicosis in 1963 . Two years later, during routine follow up, although showing no purpura, she was found to have a platelet count of 10,000 per $\mathrm{cmm}$ on two occasions.
In two weeks, the blood picture returned to normal $\stackrel{0}{\overrightarrow{2}}$ Hb $13.0 \mathrm{~g}, \mathrm{RBC} 4.62 \mathrm{~m}$, WCC 8.300 (neutrophils: $65 \%$, lymphocytes $27 \%$, monocytes $7 \%$ ), platelets: 180,000 per $\mathrm{cmm}$. Marrow examination was also? normal with active budding megakaryocytes.

In 1966 she was found to be hypothyroid and he음. platelet count again was low: Hb $11 \cdot 2 \mathrm{~g}$, PCV 39 WCC 8,400 with a normal differential, platelets 17,000. The marrow was cellular and normoblasticn with normal megakaryocytes. Antinuclear factorand Coombs tests were negative. The platelet survival time was nine days. The low platelet coun $\epsilon_{\omega}$ persisted until prednisone was started one montt? later in a dosage of $60 \mathrm{mg}$ daily. This producef remission, the platelet count rising to 335,000 i falling to uncountable levels as the prednisone waș reduced, but finally returning to normal as reduction was continued.

When last reviewed four years later (in June, 1970) no abnormal clinical findings were apparent and the blood picture was: $\mathrm{Hb} 13.4 \mathrm{~g}$, MCHC 34.3, PCV 39 , WCC 8,400 (neutrophils $72 \%$, lymphocytes $19 \%$ monocytes $8 \%$, eosinophils $1 \%$ ), platelets 17,000 .

\section{Comment}

In series of patients with apparent idiopathic thrombocytopenic purpura there are small numbers who differ from the majority by showing a normat platelet survival time. The three cases in the present: study did not show high splenic uptake of labelled platelets and the most likely explanation would appear to be a production deficit. However, witk present techniques, no megakaryocyte antibody could be demonstrated in the two patients where़ this was tested.

None of the patients proceeded to splenectomy and it is therefore not known what effect surgers would have in this atypical group; it is interesting however, that two showed no significant response to corticosteroid therapy, the third (no. 12) responded initially. These three patients have remained welp over several years without treatment.

References

Aas, K. A., and Gardner, F. H. (1956). Determination of the lifespafo of human blood platelets using labelled di-isopropylfluorqu phosphonate. J. clin. Invest., 35, 964-969.

Aster, R. H., and Jandl, J. H. (1964). Platelet sequestration in mard J. clin. Invest., 43, 843-869.

Aster, R. H., and Keene, W. R. (1969). Sites of platelet destruction fR I.T.P. Brit. J. Haemat., 16, 61-73.

Baldini, M. (1966). Idiopathic thrombocytopenic purpura. New Eng@ J. Med., 274, 1360-1367.

Cohen, P., Gardner, F. H., and Barnett, G. O. (1961). Reclassification of the thrombocytopenias by the $\mathrm{Cr}^{51}$-labeling method foD measuring platelet life-span. New Engl. J. Med., 264, 1350-135

Coons, A. H., (1958). Fluorescent ant ibody methods. Gen. cytochen? Meth., 1, 399-422.

Dacie, J. V., and Lewis, S. M. (1968). Practical Haematolog.1, 4th eq. Churchill, London. 
Dausset, J., Colombani, J., and Colombani, M. (1961). Study of Leukopenias and thrombocytopenias by the direct antiglobulin consumption test on leukocytes and/or platelets. Blood, 18, 672-690.

Harrington, W. J., Minnich, V., Hollingsworth, J. W., and Moore, C. V. (1951). Demonstration of a thrombocytopenic factor in the blood of patients with thrombocytopenic purpura. $J$. Lab. clin. Med., 38, 1-10.

Harrington, W. J., Sprague, C. C., Minnich, V., Moore, C. V., Aulvin, R. C., and Dubach, R. (1953). Immunologic mechanisms in idiopathic and neonatal thrombocytopenic purpura. Ann. intern. Med., 38, 433-469.

McKenna, J. L., and Pisciotta, A. V. (1962). Fluorescence of megakaryocytes in idiopathic thrombocytopenic purpura stained with fluorescent antiglobulin serum. Blood, 19, 664-675.

Martin, C. H., Nowicki, L., Schubert, J. C. F., and Schubert, H. (1967). Treatment of I.T.P. with actinomycin C. Germ. med. Mth., 12, 574-578.

\section{The September 1971 Issue}

\section{THE SEPTEMBER 1971 ISSUE CONTAINS THE FOLLOWING PAPERS}

Simplified organ cultures of human embryo trachea in the diagnosis of viral respiratory disease of children A. P. C. H. ROOME, VALERIE DICKINSON, AND E. O. CAUL

Observations on Aeromonas hydrophila septicaemia in a patient with leukaemia E. ABRAMS, C. H. ZIERDT, AND J. A. BROWN

Colorimetric determination of serum acid phosphatase activity using adenosine 3 '-monophosphate as substrate GRAHAM ELLIS, ALAN BELFIELD, AND DAVID M. GOLDBERG

Use of peroxidase-conjugated antiglobulin as an alternative to immunofluorescence for the detection of antinuclear factor in serum J. DORLING, G. D. JOHNSON, JANET A. WEBB, AND MAVIS E. SMITH

Use of unabsorbed radioactive marker substances in a re-assessment of the radioactive triolein test of fat absorption R. K. DITCHBURN, A. N. SMITH, AND C. J. HAYTER

Bisalbuminaemia in a Spanish family: characterization of the albumin variant J. M. IZQUIERDO, PILAR SOTORRÍO, B. DOWDING, AND A. L. TÁRNOKY

2,3-Diphosphoglycerate in acute asthma $P$. J. GALLAGHER

\section{Ultrastructure of a glomus tumour M. HARRIS}

Lymphangiosarcoma arising in chronic congenital and idiopathic lymphoedema D. H. MACKENZIE
Morgan, M. C., and Szafir, J. J. (1961). Separation of platelets from whole blood by the use of silicone liquids. Blood, 18, 89-94.

Moulinier, J. (1955). Le test de consommation d'antiglobuline appliqué a la recherche des anticorps anti-thrombocytes. Sang, 26, 811-821.

Najean, Y., Ardaillou, N., Dresch, C., and Bernard, J. (1967). The Platelet destruction site in thrombocytopenic purpuras. Brit.J. Haemat., 13, 409-426.

Richmond, J., Woodruff, M. F. A., Cumming, R. A., and Donald, K. W. (1963). A case of idiopathic thrombocytopenia and autoimmune haemolytic anaemia treated by thymic irradiation and by administration of imuran and actinomycin-C. Lancet, 2, $125-128$.

Shulman, N. R., Marder, V. J., and Weinrach, R. S. (1964). Comparison of immunologic and idiopathic thrombocytopenia. Trans. Ass. Amer. Phycns, 77, 65-78.

van de Wiel, W. M., van de Wiel-Dorfmeyer, H., and van Loghem, J. J. (1961). Studies on platelet antibodies in man. Vox Sang. (Basel), 6, 641-668.

Copies are still available and may be obtained from the PUBLISHING MANAGER, BRITISH MEDICAL ASSOCIATION, TAVISTOCK SQUARE, WC1H 9JR price 105p.

Haemangiosarcoma of breast E. KESSLER AND I. L. KOZENITZKY

A micro-method for peripheral leucocyte migration in tuberculin sensitivity $\mathrm{K}$. FEDERLIN, R. N. MAINI, A. S. RUSSELL, AND D. C. DUMONDE

Phenacetin-induced haemolytic anaemia R. J. L. DAVIDSON

Laboratory control of heparin therapy M. J. O'SHEA, P. T. FLUTE, AND G. M. PANNELL

Single-sample diagnosis of recent rubella by fractionation of antibody on Sephadex G-200 column J. D. GUPTA, V. PETERSON, MARILYN STOUT, AND A. M. MURPHY

Manpower in pathology 1969-1975 C. L. GREENBURY

Technology of a regional Guthrie test service R. L. NEWMAN AND D. J. T. STARR

\section{Technical methods}

Estimation of blood phenylalanine from a dried blood spot using the Guthrie test LEMAG WORKING PARTY. A rapid silver impregnation technique for oligodendrocytes, microglia, and astrocytes T. SCOTT

A rapid method for the detection of ferritin in serum M. R. BEAMISH, P. LLEWELLIN, AND A. JACOBS

Book reviews 